\title{
ARTIGOS
}

\section{A INTERPRETAÇÃO CRISTÃ DA HISTÓRIA (III) $\left({ }^{\star}\right)$.}

(Continuação)

III. - OS AGENTES DA HISTÓRIA.

A: - CONCEPÇÕES NAO-BABLICAS.

E' óbvio que alguma coisa está se passando na História. Mas qual é a fonte ou origem do processo histórico? No mundo ocidental, onde a vida histórica atingiu o mais alto grau de auto-consciência, pensa-se que a existência histórica é um reino à parte, diferente e superior ao da natureza apenas. Não é de se admirar, portanto; que atualmente no Ocidente se considere o próprio homem como o autor e o senhor da História.

Há divisão de opiniões, entretanto, quanto ao papel exato do homem. Alguns atribuem $o$ processo histórico à decisão de indivíduos, enquanto outros pensam que é através dos anseios mais ou menos inconscientes de corpos coletivos que a História se mantém em movimento. Ranke, Treitschke, Carlyle, Taine e Gobineau, foram alguns dos representantes clássicos da primeira concepção, enquanto que Herder, Hegel e Marx adotaram a última. Existe nos tempos recentes a tendência de atenuar o personalismo exagé: rađo do século XIX. Sob a influência da psicologia moderna o marxismo foi reinterpretado como tendo origem em aspirações subconscientes, que se manifestam ùnicamente pela discussão e crítica recíproca. De modo semelhante, Bergson ou Ortega y Gasset preferem falar de um elã vital inconsciente, ou do "espírito da juventude" como o verdadeiro agente da História. Em conseqüência, os indivíduos excepcionais são considerados apenas como símbolos ou indícios do movimento coletivo; Lenine, por exemplo, foi apenas o "expoente da Revolução Bolchevista".

Estas interpretações humanísticas da História são postas ém dúvida, porém, pelos que por um estudo cuidadoso dos desenvolvimentos históricos aprenderam a avaliar o lugar ocupado por fatô-

(*). - Este é o terceiro artigo de uma série de palestras proferidas pelo Prof. Otto A. Piper no Salão Nobre da Faculćade de Filosofia, Ciências e Letras da Universidade de São Paulo em agôsto de 1953. Texto em inglês traduzido por Percy Fávero Schützer (Nota da Redação). 
res não-pessoais na vida dos povos. Montaigne já havia assinalado: o papel desempenhado pelo habitat, condições geográficas, clima. experiências passadas, na vida histórica das nações. Esta percepção levou ao desenvolvimento das várias escolas naturalísticas e materialísticas dos séculos XIX e XX. Reduzindo a vida histórica ao ritmo do repto e resposta, Toynbee adotou no todo a mesma concepção. De acôrdo com êle os povos são dirigidos pelo curso dos acontecimentos e circunstâncias em direção à tarefa que tem. de executar. Naquelas condições pode parecer que o homem tem a liberdade de não considerar o repto de uma șituação, mas êle. descobrirá logo que agindo assim o faz em seu próprio prejuízo. $\mathrm{O}$ papel de mera reação assim atribuido à espontaneidade humana parece implicar em que a capacidade criadora e a auto-determinação humanas, que alguns consideram como fatôres decisivos da vida. históriça, sejam apenas ilusões.

Os gregos antigos achavam que o curso dos acontecimentcs. não dependia tanto do que o homem realizasse mas antes, que independentes de seus esforços ou passividade, as coisas aconteciam imprevizível e soberanamente. A Sorte ou o Acaso ou o Infortínio presidiam respectivamente sôbre os destinos dos indivíduos e nações. Pascal, tạmbém, impressionou-se profundamente com o que lhe parecia ser o caráter absolutamente contingente da vida histó-: rica: acontecimentos completamente fortúitos como, e. g., a morte; súbita de Gustavo Adolfo ou de Cromwell, trouxeram uma mudança radical do curso da História. Alguns, porém, perguntarão se êsses acontecimentos ocasionais mudaram na realidade a História, ou se apenas contribuiram para acelerar o advento de futuros desenvolvimentos. Também, objeta-se que em muitos outros exemplos as. reviravoltas da História resultaram de ações deliberadas e não de. acontecimentos irracionais.

Cada uma dessas concepções contém certos fatos inegáveis. que podem ser citados como provas a seu favor. Esta circunstância sugeriria que a agência histórica é um fenômeno complexo e' que seria aconselhável adotar a idéia do "Campo histórico", concepção cujas raízes estão nas filosofias modernas da totalidade ou Ganz-heit (e. g., Othmar Spann, Jan Christian Smuts). A idéia do "campo histórico" formou-se por analogia com o "campo eletro-magnético" ou o. "campo de gravitação" na física moderna. O povo, sua terra e sua história são suas partes constituintes mais impor-. tantes. Em conseqüência, a vida histórica é um processo no qual. o povo agente e seu meio formam uma unidade dinâmica cuja operação se manifesta tanto nos acontecimentos naturais como nos históricos. Estas duas espécies de acontecimentos devem ser difererciadas para fins de análise, mas não existem independentes uma da outra. Com sua condição natural e seu passado histórico um. 
grupo histórico forma um campo que tem sua dinâmica próprie, recursos e direção. Sòmente pela interrelação das partes constituintes e por sua relação respectiva com o todo é possivel entender a história de um grupo ou nação.

Embora a idéia do campo histórico seja mais compreensiva do que tôdas as cutras concepções da atividade histórica, ela é, todavia insatisfatória do ponto de vista das pessoas ativamente emperihadas na Fistória. Como muitas outras concepções da História ela originou-se no estudo, e é uma tentativa da parte do historiador ou filósofo de explicar o que outros fizeram na História. Aquêles, porém, que tomam parte ativa na vida pública e na História, mantém a crença incorrigivel đe que o agente histórico năo é apenas uma função do campo histórico, mas, antes, que ùnicamente através de suas ações é atribuído sentido ao processo histórico. Além disso, agindo de acôrdo com um propósito, e tendo em mente certos fins ideais, êstes agentes históricos não se satisfazem com o sucesso pessoal. Crêm que estão trabaihando para um objetivo definido. Finalmente, a idéia do campo histórico, pelo menos quando interpretada de acôrdo com Dr. Zuckermann, implica numa indiferença para com os valores. Quando se considera o campo" histórico como uma entidade contida em si mesma, pode-se atribuir sentido a seu movimento sòmente quando se admite que o material de que se compõe a História é por natureza bom. Hegel, a quem a idéia do campo histórico deve muito, compreendeu que em tais circunstâncias os males não podem verdadeiramente ser maus. Servem, no seu aspecto desagradável, como um estímulo para o progresso. Todavia, a vida histórica se baseia em grande medida na experiência da inimizade que conduz à crença de que o objetivo por que luta o adversário é absolutamente incompatível com o meu próprio. Em outras palavras, recusamo-nos a ver qualquer valor positivo nos males inflingidos por outros; também não se pode dizer que é sempre benéfico para o vencedor adotar a natureza ou os métodos do vencido. Nestes aspectos todos, a concepção bíblica é mais fiel aos fatos do que estas interpretações humanísticas ou naturalísticas.

\section{B. - CONCEPCEÃO BABLICA.}

Não é de modo nenhum óbvio que exista uma concepção bíblica da atividade histórica. A Bíblia não se entrega a especulações filosóficas acêrca da História nem apresenta uma hipótese especial que explique seu curso. Contudo, há uma idéia muito clara da atividade histórica, particularmente entre os escritores do Novo Testamento. Distinguem êles três agentes, a saber: Deus, o Homem e o Diabo, e atribuem a cada um uma função bem defini- $\therefore$ 
da. Deus é cultuado como o Senhor da História, o homem é considerado o autor da História; e o Diabo é temido como o poder perturbador da teleologia intrínseca e da harmonia da História. Uma vez que os três agentes estão, por sua natureza, em relação com êste mundo, as histórias da Bíblia nunca perdem de vista o ambiente natural em que a História se desenvolve. De modo análogo, os três agentes não são considerados cómo mônadas, isto é, como se apenas incidentalmente tivessem entrado em contacto um com o outro. A idéia da criação liga-os permanentemente. Assim a noção de um campo histórico aplica-se à concepção bíblica da História, mas contrapondo-se a uma interpretação puramente imanentista de sua dinâmica, esta leva em conta também suas energias transcendentes. O campo não é confinado a fatôres puramente "naturais".

\section{I. - Deus.}

O Deus da Bíblia é descrito como o Senhor da História. Embora não seja êle mesmo um fator da vida histórica, guia-a de tal ${ }^{*}$ modo que ela se move para um fim objetivo e transcendente. Igualando as manifestações divinas com as dos anjos, porém, o Velho' Testamento já dá ênfase ào fato que Deus não deve ser considerado como parte ou função dêste mundo. Todavia a idéia bíblica de um Criador torna possivel atribuir-se um fim objetivo à História, isto é, que transcende essencialmente os anseios e aspirações dos que nela trabalham. Duvidando da possibilidade de ser Deus o Senhor da História, Platão não teve outra alternativa senăo a de negar que o homem pudesse jamais atingir seu destino por meio da atividade histórica. Os neo-kantianos encobrem o problema falando de uma "aproximação assintótica" do objetivo, pela qual é dado ao indivíduo apreciar a distância real que separa suas realizações do objetivo.

Como o Senhor da História, Deus é a garantia de um significado último objetivo da História, apesar da fraqueza natural do homem e de sua falta de experiência e apesar das perturbações freqüentes do movimento regular da História ocasionadas pelo Diabo. Uma vez que o homem é criado por Deus e está assim sujeito a Seu propósito, a História ocorre onde quer que homens vivam juntos, e ela tem a mesma estrutura é natureza através das idades e por tôda a terra. De modo semelhante as condições sob as quais se desenvolve a História, não são fruto do acaso mas resultam do fato. de Deus ter feito o homem e êste mundo como êles são. Assim a História se realiza dentro de um sistema fixado permanentemente por Deus. O sonho de Prometeu de ilimitada liberdade portanto 
nunca se converterá em realidade. O Criador restringiu 'o alcance da atividade humana.

O Deus que a Bíblia revela é um ser pessoal que age de acôrdo com um propósito. Assim êle é capaz de estabelecer um objetivo para as coisas que criou. Como resultado do lugar especial que Deus concedeu ao homem neste mundo, a História se move para um objetivo último e serve um plano divino. Por isso, a necessidade histórica não deve ser identificada com a das leis da natureza. Este foi o engano básico do estoicismo, por exemplo, que o impediu de apreender a natureza da História. E' certo que o homem é incapaz de alterar o caráter do campo histórico ou de estender substancialmente o domínio que the foi fixado para a atividade histórica. Mas ao contrário do determinismo rígido que se encontra na esfera não-humana da natureza, o homem é capaz de ajustar-se às condições fixadas pela natureza. A afirmação do homem de sua superioridade sôbre as fôrças da natureza e condições naturais dêste mundo constitui um dos aspectos essenciais da vida histórica.

Contudo, a despeito desta liberdade encontra-se um tipo superior de necessidade na História. Nada de valor duradouro e verdadeiro pode ser realizado na História, exceto quando é feito em submissão à vontade de Deus. A História prova que o homem é vítima de um êrro fatal quando crê que é livre de escolher seu fim último. Por maior que seja o sucesso temporário, ações feitas à revelia de Deus terminarão inevitàvelmente em fracasso. Hegel já tinha observado que na vida histórica o homem age sempre tendo em vista, além de um objetivo próximo, um fim último. Quando Toynbee pretende que o grupo histórico é desafiado pela situação histórica, êle deixa de considerar que o objeto pelo qual o homem é desafiado - cada objeto é um obstáculo e por isso um desafio à sua vontade - não indica a direção em que o homem deve se mover. Quer êle faça um ataque frontal, o circunde, ou retroceda, estará reagindo ao desafio do objeto. A escôlha do meio ou método errado pode resultar em recuos temporários; mas o sucesso ou fracasso na História não é determinado por isso. Dependem do objetivo que o grupo histórico tem em mente. Mas o verdadeiro objetivo de uma ação é uma realidade que concerne bem como transcende tanto o sujeito como o objeto. Sòmente aquêles que conhecem o objetivo de Deus são assim capazes de reagir adeqüadamente ao desafio dos acontecimentos.

A soberania divina implica na certeza de que o objetivo estalecido pelo próprio Deus acabará por ser atingido porque êle tem poder sôbre tôdas as criaturas, a despeito das dificuldades que seu plano encontra. Vista de uma perspectiva puramente humana a 
História é um cemitério de projetos e esforços ambiciosos. Todavia, tendo em vista os objetivos finais de Deus, as catástrofes da História são tão importantes como suas realizações positivas. Elas libertam as energias daqueles que até então tinham sido incapazes de trazer contribuições construtivas para a História porque eram dominados e impedidos pelos "grandes poderes". Não há situações sem saída na História quando esta é vista segundo a perspectiva de Deus, e tudo é bom precisamente do modo pelo qual acontece (Ecl. 3. 14). Este fato não implica, porém, em que, num sentido hegeliano, tudo na História serve como estímulo para novas criações. Antes muito do que acontece na História é um julgamento divino daqueles que ocupam momentâneamente o poder.

Além disso, a soberania de Deus explica o fato de ser o homem absolutamente incapaz de predizer a História futura, por melhor que conheça todos os elementos que constituem o campo histórico. E' simplesmente absurdo esperar que por meio de estatísticas e sociologia a História possa um dia ser previzível. Pela mesma razão a História é em última análise incontrolável. A educação e a diplomacia podem contribuir para estabelecer uma certa ordem num dado tempo. Mas os campos históricos pròpriamente estão além do contrôle do homem; como se pode ver, por exemplo, na súbita erupção do problema racial na África do Sul, na exigência de independência do Cambodge, na revolta dos trabalhadores em Berlim em 1953. O poder do homem não ultrapassa sua capacidade subseqüente de ajustar suas ações a tais acontecimentos incontroláveis.

Finalmente, a soberania de Deus implica em que êle usará os grupos históricos como seus instrumentos ao executar seu propósito. Isto quer dizer, os fins específicos que as nações buscam na História não são fins últimos. Isto é verdade, não apenas a respeito dos objetivos próximos, mas também em relação aos ideais que os homens aspiram em suas atividades históricas. A política de população de Ciro, e. g., foi usada por Deus como um meio de restabelecer seu povo escolhido, (Isa. 41), ou o sonho imperialista de Carlos Magno lançou os alicerces de uma Igreja que acabaria por cristianizar tôda a Europa e produzir um novo tipo de cultura cristã.

\section{II. .. O Homem.}

Na História da Filosofia encontramos uma longa e influente tradição na qual o indivíduo é tratado como uma entidade contida em si mesma. Como conseqüência, a vida histórica é interpretada como a obra de indivíduos grandes e poderosos. Mas é óbvio que tal concepção se baseia numa generalização errônea de certos fatos. 
Com relação a resultados há uma diferença considerável, por exemplo, entre o indivíduo crítico de sua época de um lado e o artista criador ou o homem de estado de outro. O primeiro formula sua crítica sem levar em conta a situação histórica. Sua impaciência ou suas elevadas exigências podem causar uma agitação temporária, mas êle não trará uma contribuição duradoura para o processo histórico. Ao contrário, o grande artista ou o genuino homem de estado brotam do solo comum. Embora possam por algum tempo ser impopulares, transformarão, todavia, seu grupo porque sentem de um modo bem intenso sua dinâmica e suas necessidades e anseiam por melhorar suas condições.

Além disso, há certos fatos na vida histórica que indicam que a concepção coletivista não está completamente errada. Foi pelo estudo da História que os românticos, e. g., foram levados a falar de uma coisa como "vida nacional" ou o "gênio de uma nação". Os "membros de uma nação tem certas características comuns não compartilhadas por nenhuma outra nação. Por isso não há duas nações que reajam a uma mesma situação exatamente da mesma maneira, por íntima que seja a relação racial ou cultural de uma com a outra, ou por grandes que sejam seus interêsses comuns. Em nossos dias, e. g., uma comparação das atitudes britânica e norteamericana diante dos problemas internacionais é muito instrutiva.

A Bíblia faz justiça àquêles aspectos aparentemente contraditórios da História descrevendo-a como um processo no qual as coletividades estão empenhadas, todavia, elas dependem dos indivíduos que realizam um certo número de funções dentro da coletividade e em seu favor.

No centro do relato bíblico encontramos o povo escolhido de Deus. As narrativas do Pentateuco que precedem à formação de Israel ocupam-se da preparação de Israel como uma nação e das razões históricas que tornaram sua gênese necessária. De modo semelhante o Novo Testamento descreve como, de acôrdo com o plano de Deus, Jesús surgiu como o Messias dos judeus, isto é, êle é considerado numa missão histórica; mostra-nos ainda o Novo Testamento como mediante seu ministério Jesús foi instrumento para transformar completamente o povo de Deus, de modo que messe povo fôssem incluídos membros de tôdas as nações. Os protestantes modernos raramente compreendem o quanto seu individualismo religioso difere da mensagem do Novo Testamento.

Esta idéia de um povo escolhido também não deve ser tomada como um fenômeno único e excepcional na História. $O$ ato de escolher uma nação destina-se a manifestar a função histórica de tôdas as nações. Pela própria existência histórica do povo escoIhido não sòmente a centralidade da vida coletiva mas também a verdadeira natureza da existência nacional é sublinhada. Mostra- 
se por êsse meio que uma nação é uma coletividade constituida por uma lei. A vida verdadeira é a vida dentro da coletividade. Ainda que os últimos escritores do Velho Testamento mostrem que Deus concedeu ao indivíduo o privilégio de se tornar uma pessoa, a vida pessoal não é por isso concebida em têrmos de individualismo. E' pela obediência à lei nacional e no trato com as instituições e membros do povo que a verdadeira vida pessoal é vivida.

Com respeito a isto dois característicos merecem especial menção. Primeiro, o Velho Testamento mostra que é pela aceitação da lei de Deus que Israel adquiriu a condição de nação em sentido eminente. Em outras palavras, uma nação torna-se articulada na História sujeitando-se às exigências de uma lei. Seus feitos militares, suas realizações culturais, e mesmo sua religião não são importantes por si mesmos mas sòmente quando relacionados com os objetivos da lei. Tal concepção da História é absolutamente única. A maioria dos historiadores considerarão, de acôrdo com suas filosofias, a história militar, cultural ou religiosa como o assunto principal de seu estudo, enquanto que aos escritores bíblicos interessa em primeiro lugar a justiça de uma nação. Ao mesmo tempo, porém, não medem a nação por uma lei ou ideal abstrato, como faz, e. g., Hegel. E' antes a lei real da nação que serve como padrão. Assim uma nação poderá julgar seu próprio valor a qualquer momento, enquanto que outras perspectivas têm que deixar a avaliação da vida nacional ao julgamento retrospectivo das gerações subseqüentes. A única alternativa - a que freqüentemente se recorre - é a de julgar uma nação por suas realizações momentâneas. Êste método é puramente subjetivo, e não é de se admirar que o mesmo fato, e. g., nossa civilização tecnológica seja amargamente criticada por alguns e exaltada como uma realização maravilhosa por outros. Se, contudo, tivermos em mente a correlação entre nação e lei, aquela civilização não será considerada como um fim em si mesma mas antes como um meio de tornar a vida nacional articulada, e assim a pergunta básica será, que contribuição traz ela para o desenvolvimento do império da lei na nação.

A segunda conseqüência da concepção bíblica de nação é a idéia de que há solidariedade de todos os membros da nação no que concerne à execução da lei. As exigências da lei podem variar de grupo para grupo e de classe para classe. Mas espera-se de cada cidadão plena obediência às exigências da lei. Em outras palavras, contrapondo-se àquelas concepções de coletividade históricas em que se dá ênfase às motivações inconscientes e subconscientes, a concepção bíblica, embora não negue tais impulsos considera-os, porém, de menor efeito històricamente do que os atos conscientes de obediência à lei. E' por êstes últimos atos que uma nação se eleva do nível de uma unidade biológica para o de uma unidade 
histórica. Um fato concomitante é a responsabilidade pessoal que é assim atribuída a cada membro da nação. Dirigindo-se a cada um dos membros de uma nação, a lei nacional eleva cada um dêles à dignidade de um agente histórico. Encontramos assim na Bíblia uma concepção na qual a coletividade e o indivíduo são mantidos em equilíbrio como agentes históricos. E' esta a única concepção da História em que a importância do homem comum é plenamente reconhecida. Embora os antigos romanos, e. g., se vangloriassem de sua lei, pensavam nela primàriamente em têrmos de ùma instituição que devia ser imposta pelas autoridades e não em têrmos de responsabilidade pessoal. Anàlogamente na propaganda bolchevista faz-se muito barulho em tôrno do significado do homem comum para o advento de uma nova éra. Mas a lei decretada pelos cómunistas não é uma lei nacional livremente aceita. Antes sua "lei" representa a vontade de uma minoria imposta ao resto da nação. O papel do homem comum confina-se, pois, ao de ser controlado efetivamente por um govêrno, cuja vigilância policial produz uma conformidade externa.

A concepção bíblica do grupo como o sujeito da atividade histórica deixará completamente de lado o significado dos "grandes homens"? Longe disso. Os relatos bíblicos têm muito o que dizer sôbre os inđivíduos que moldaram o curso da história da salvação. Mas de acôrdo com o que foi dito acêrca da concepção bíblica do grupo histórico, tanto a função como a natureza dos "grandes homens" aparecem em uma perspectiva diferente das interpretações seculares da História. Muito se destacam na Bíblia três tipos de grandes homens, a saber, os "homens de Deus", os "representantes" e os "originadores". Nota-se em cada exemplo que o papel desempenhado por êstes indivíduos depende não apenas do que são por si mesmos, mas também de sua relação com Deus e com seu grupo.

Há primeiramente os "homens de Deus". Lemos com grande freqüência na Bíblia de homens e mulheres que Deus levantou enchendo-os de seu Espírito e que se tornaram assim os guias de seu povo. Agiram em várias funções, e. g., como líderes políticos ou militares (Moisés, os Juízes, Daví, etc.), ou como guias espirituais (profetas, apóstolos, evangelistas, etc.). De acôrdo com o fato que o grupo histórico é determinado primàriamente por sua relação à sua lei, aquêles que se destacaram nos campos da civilização ou do comércio desempenham apenas um papel secundário. De modo análogo, embora os cabeças políticos possam ter que atuar também como chefes militares, seus feitos no campo de batalha não são celebrados. Por sua vez, o enigmático mistério do poder pessoal é explicado como uma dádiva divina, não como coisa alcançada pelo indivíduo, e que será portanto retirada por Deus quando o indiví- 
duo não servir : ao propósito de Deus para com seu povo ou quando sua missão estiver terminada.

Anàlogamente, é muito interessante a função atribuída aos "representantes". Em Gênesis 18, e. g., Abraão intercede junto de Deus para que poupe Sodoma se, cinqüenta, quarenta ou pelo menos dez justos fôrem nela encontrados. Assim o destino da cidade dependerá da intercessão bem sucedida de um indivíduo que pode falar em seu nome, ou de um punhado de cidadãos que agem de acôrdo com suas leis básicas. Freqüentemente ouvimos também falar de um "remanescente" justo do povo que será salvo, e ainda é como o justo que Jesús é descrito como o Salvador do povo escolhido de Deus. A idéia subjacente a todos êstes exemplos é a mesma, a saber, que todos: os que se identificam com a lei do grupo histórico tornam-se por isso seus verdadeiros representantes. Neles o grupo continua a existir e por sua causa a catástrofe iminente é desviada ou uma nova oportunidade oferecida. Estes representantes não foram escolhidos por voto; desempenham aquela função porque tomaram sôbre si a lei de seu grupo. São sempre poucos em número; mas ainda que num sentido poder-se-ia dizer que o total dos membros de um grupo histórico o constitui como o sujeito da vida histórica o destino final do grupo depende da presença dêsses "representantes". Eles tornam realidade aquilo que por sua lei o grupo reconhece como justo. Assim através de sua existência torna-se evidente que o valor do grupo não depende de sua lei como tal mas antes da obediência de seus membros a essa lei. Assim os representantes dão o exemplo pelo qual os outros membros do grupo são desafiados a viver à altura dos padrões expressos por sua lei básica. Por sua vez, o infortúnio atingirá uma cidade ou nação quando esta não desaprovar a conduta injusta ou iniqua de seus representantes, e. g., seus governantes.

Há, finalmente, os "originadores". Os escritores bíblicos vêm que nem todos os indivíduos influenciam a estrutura da História do mesmo modo. Os grupos históricos não são interpretados como tendo se formado pela agregação casual de um número de indivíduos. Antes há certas pessoas raras que são capazes de pôr seu sêlo sôbre sua posteridade, de modo que o que parecia ser um aspecto incidental em suas vidas torna-se um característico permanente de seus descendentes. Além disso, aquêle característico se torna o vínculo de unidade que os mantém ccesos num grupo histórico. Esta capacidade de dar origem é também uma dádiva divina. Não pode ser explicada por fatôres biológicos ou sociológicos. Tão decisivo é o papel do originador que o grupo pode ser chamado por seu nome, por exemplo, o povo de Israel é chamado Jacó (e. g., Ps. $78: 5 ; 85: 1$; Isa. 40:7) e por sua vez a Igreja é chamada de Corpo de Cristo. Diferindo dos gênios nas esferas das artes e da ciência 
que têm seguidores, os originadores formam para êles um povo, e uma vez que povo e lei estão correlacionados, sua função não é apenas biológica. Ela influi na obediência do povo à sua lei. Assim Adão, e. g., não é sòmente o originador de uma humanidade unificada mas também aquêle através do qual o pecado, isto é, a rebelião do homem contra a vontade de Deus se torna um característico ccmum a todos os sêres humanos. De modo semelhante Abraão, aceitando o rito da circuncisão, penhora sua descendência ao serviço de Jahve. Jesús, finalmente, tem o poder de transformar de tal modo os sêres humanos que êle se torna o cabeça de uma "terceira raça".

\section{III. - O Tiabo.}

Para o homem moderno um dos característicos mais estranhos e menos agradáveis da concepção bíblica da História é o papal importante atribuído a um Diabo pessoal. Porém devemos ter em mente que é no Novo Testamento mais do que no Velho que há referências bastante freqüentes ao Diabo ou Satanás. E' claro que fci sòmente à luz da revelação plena trazida por Jesús Cristo que a função do Diabo pode ser clara e completamente reconhecida. E' possivel que a princípio os judeus tivessem conhecimento da idéia de um adversário pessoal de Deus, quando através de seu contacto com os persas ouviram falar da religião de Zoroastro. Mas é claro que, como em muitos outros casos, não adotaram a idéia simplesmente mas antes a reinterpretaram completamente e reformularamna para integrá-la na sua concepção de Deus. O Diabo do Velho Testamento é o acusador e o tentador do homem antes que a fonte do mal. A crença na operação do Diabo permitiu aos escritores do Novo Testamento e a seus seguidcres tornarem-se conscientes de característicos essenciais da História que outros ou ignoraram ou mal interpretaram, a saber, a presença de um elemento irracional ou disteleológico na História, o absurdo de crer em uma melhoria natural e inevitável da História e, finalmente, a operação de uma energia antidivina na História.

Há em primeiro lugar, pois, o fato estranho de que o curso da História não é nem totalmente racional nem completamente irracional. Observamos o homem lutando por objetivos elevados e alcançando sucesso em seus esforços, pelo menos em parte. Porém é também verdade que grupos históricos, e. g., os aztecas, deixem de existir e sua obra não é continuada por outros. Além disso, já os antigos ficavam perplexos ante o papel demasiadamente grande desempenhado pelo acaso, pela boa e má sorte na História. Além disso há os males diversos com que a natureza dificulta o caminho da História, e. g., fomes, doenças, terremotos, inundações e os males 
provàvelmente piores que os da natureza por meio dos quais a desumanidade do homem para com o homem torna a vida miserável. Tudo isto se torna mais surpreendente ainda porque êstes fatos se dã̃o em um mundo governado por leis estritas, em um universo onde há abundância de coisas boas e numa humanidade que estabelece um prêmio para a bondade moral.

Em segundo lugair, grande parte da vida histórica é dedicada aos esforços do homem para restringir os males dêste mundo e tornar a vida racional. Poder-se-ia mesmo dizer que na tecnologia, ciência e organização êstes objetivos se tornaram a obseção da humanidade civilizada moderna. Mas os escritores do Novo Testamento rejeitam a idéia de que seja inerente à História um movimento para uma condição essencialmente melhor ou que cêdo ou tarde os esforços heróicos do homem para controlar os fatôres irracionais da História o levem a triunfo real sôbre êles. Ao contrário, a experiência mostra que não obstante sucessos e vitórias temporárias, a História se encontra sob o domínio da "lei de eqüalização", segundo a qual todo o progresso cultural ou social do homem ou qualquer nova descoberta será usada tanto para maus como bons propósitos. Como conseqüência se pode dizer que por mais poderosa que se torne a humanidade e por mais admiráveis que sejam as descobertas da ciência, os homens não se sentirão mais felizes por isso, porque existirão os mesmos fatôres irracionais pelos quais serão determinadas suas vidas através dos tempos.

Em terceiro lugar, estas condições históricas não podem ser explicadas apenas como consequiências de males naturais ou de imperfeições do homem. Porque não se pode negar que na natureza a abundância de coisas boas sobrepuja em muito os males. E também fatôres irracionais como a sorte ou ol infortúnio nada têm que ver com o valor natural das coisas que as ocasionam. Acima de tudo é absurdo atribuir as deficiências e limitações do homem moderno exclusivamente à imaturidade da mente humana. A raça humana existe há mais de 100.000 anos e assim já devia ter ultrapassado seu período de infância, mas a despeito dêste longo desenvolvimento a humanidade foi incapaz de vencer a operação da lei de eqüalização. Assim o elemento irracional presente na História deve ser atribuído a um fator que está acima das coisas e sêres terrestres, e capaz de controlá-los. Contudo, ainda que o Novo Testamento indique a relação estreita entre os males dêste mundo, de. um lado, e o Diabo de outro, seus escritores não compartilham do "dualismo ingênuo" que considera o Diabo como a fonte de todos. os males. De acôrdo com o Velho Testamento vêm a origem do mal em parte na vontade livre do homem por meio da qual êle. comete pecado e em parte na maldição que Deus pronunciou contra o homem pecador e que resulta em uma vida neste mundo em- 
baraçada por dificuldades, perigos e sofrimentos. Segundo a concepção bíblica da vida, a função de Satanás consiste em enganar e tentar o homem. Ele engana as pessoas usando a coexistência de coisas boas e más neste mundo como um artifício para confundí-los acêrca do verdadeiro valor das coisas. Assim coisas que por efeito de seu engano aparecerão para a maioria como bens não adulterados, e. g., a riqueza ou o poder, são desmacaradas pelos escritores bíblicos como estando cheias de perigos, enquanto que por outro lado os crentes são avisados que muitas coisas que os atemorizam não merecem nossas preocupações e cuidados.

A razão porque o Novo Testamento fala tão claramente de um Diabo pessoal antes que de uma Falsidade (pseudos) impessoal e transcendente, reside primàriamente no fato de que aquilo que parece ser apenas irracional e contraditório na História revela um caráter disteleológico quando examinado mais de perto. A natureza da História é tal que faz com que o propósito de Deus, de ter uma humanidade que viva em harmonia com o Divino, seja constantemente obstruido e frustrado. A História apresenta harmonia em pequena escala e temporàriamente mas nunca em escala universal e permanente. Satanás é chamado de enganador não apenas porque a aparência das coisas não coincide com sua verdadeira natureza, comó Platão ou o hinduismo afirmaram, mas porque Satanás usa êsse fato para sugerir que as coisas dêste mundo tem sua importância' em si mesmas. Ele é chamado o "príncipe dêste mundo" porque faz com que as coisas terrenas pareçam tão importantes que o homem não se preocupa com uma interpretação transcendental. A energia exibida pelas fôrças hostis da natureza, por exemplo, parece ser tão grande que o homem médio nem mesmo tenta pensar que poderia haver um outro poder controlando-as. Por sua vez os "grandes homens" da História usam o imenso poder a seu comando como se êles o tivessem gerado. Ao leitor médio de nossos jornais a imagem da História neles apresentada cada dia parece ser a explicação mais plausível da vida histórica. Mas o resultado de tal aparência é que quanto mais intensamente as pessoas se envolvem na vida histórica com maior facilidade se afastam de Deus. O Diabo de que fala a Bíblia não é porém um anti-Deus como nas religiōes dualistas. Segundo a Bíblia existe um dualismo no mundo criado por Deus mas êste continua a ser o senhor soberano da História. A veracidade desta concepção pode ser vista no fato de que as operações do Diabo pressupõem a existência dêste mundo e do plano de Deus para o mesmo. Falta ao Diabo habilidade criadora. Ele é sòmente capaz de perverter a bondade já existente. Assim seu, poder é de limitada duração. Jesús Cristo o fará cessar. 


\section{IV. - Jesús Cristo.}

A imagem da atividade histórica que a Bíblia apresenta estaria incompleta se não nos referíssemos a Jesús Cristo. Os teólogos em geral falam dêle sòmente como o redentor e salvador de almas individuais. Mas no Novo Testamento êle é também descrito como um que veio para destruir as obras do Diabo (I João 3:8), e particularmente no Apocalipse êle é descrito como conduzindo a História para um glorioso fim. Uma vez que êle é o Filho de Deus incarnado, sua presença na História significa que a harmonia providencial do humano e do divino tornou-se uma realidade e assim que nele a lei da eqüalização foi invalidada e a História atingiu um nível novo. Em seu ministério histórico êle é apresentado como combinando em si mesmo os três tipos de grandes homens descritos acima. Ele é "enviado por Deus" para livrar o povo de Deus dos assaltos de fôrças hostis e para organizá-lo para ação histórica, êle é a fonte de nova vida através da qual as pessoas renascem ou são transformadas, e em sua própria vida sem pecado êle representa a verdadeira natureza do povo de Deus. Assim através de seu ministério um novo processo na História foi iniciado. Livrando os homens dos enganos do Diabo êle liberta energias divinas em suas vidas e assim os capacita também a invalidar a terrível "lei da eqüalização". Ao mesmo tempo como o enviado de Daus para introduzir o reino celestial êle certamente comunica um caráter escatológico à História. Ao contrário de outros grandes homens, que apenas elevam os homens a um nivel relativamente mais alto de existência histórica ou que lhes dão temporàriamente um novo impulso, êle tem o privilégio de tornar possivel aos que o seguem viver com Deus e por meio de sua vida de fé tornar completa a História. Nele, e nele sòmente, tem a raça humana a garantia de que tôdas as aspirações e esforços da História humana atingirão um fim perfeito. Assim temos a certeza de que a vida histórica tem um sentido objetivo. Ainda que a consumação escatológica transcenda as condições da vida histórica que experimentamos agora, a vida incarnada de Jesús Cristo nos dá a certeza de que o fim último da vida humana não é um céu platônico, em comparação com o qual tôda a vida histórica é irrelevante. Antes a esperança cristã aguarda a volta de Cristo, isto é, uma transformação completa da vida histórica que será análoga àquela mudança radical da raça humana que se deu com sua Incarnação.

(Continua no próximo número).

OTTO A. PIPER

Professor de Literatura e Exegese do Novo Testamento no Seminário Téológico de Princeton (Estados Unicios). 